\title{
A Novel Three-Phase Doubly Salient Permanent Magnet Machine for Wind Power Generation
}

\author{
K. T. Chau, Ying Fan \\ Department of Electrical \& Electronic Engineering \\ The University of Hong Kong \\ Hong Kong, China \\ ktchau@eee.hku.hk, yfan@eee.hku.hk
}

\author{
Ming Cheng \\ Department of Electrical Engineering \\ Southeast University \\ Nanjing, China \\ mcheng@seu.edu.cn
}

\begin{abstract}
This paper presents a novel 3-phase 12/8-pole doubly salient permanent magnet (DSPM) machine for application to wind power generation. The key is to design and analyze the proposed DSPM generator, namely the design of a novel machine structure to achieve high power density and high robustness, and the devise of system operation to attain high efficiency. By using finite element analysis, the static characteristics of the proposed generator are given. Hence, the evaluation of system performances is conducted by computer simulation. Experimentation is also given to verify the validity of the proposed DSPM generator.
\end{abstract}

Keywords-Doubly salient motors; permanent magnet machines; wind power generation.

\section{INTRODUCTION}

With ever increasing concerns on energy crisis and environmental protection, the development of renewable energy resources has taken on an accelerated pace. Wind power is one of the most viable renewable energy resources. For wind power generation, the core element is the wind power generator. The conventional generators, such as the synchronous generator and induction generator, are mainly designed for constant-speed turbine operation so that they are inefficient or even ill-suited for variable-speed wind turbine operation. Therefore, an efficient generator particularly for wind power generation is highly desirable. In [1], the switched reluctance (SR) machine was proposed for wind power generation because of its advantages of robustness, brushless and high reliability. In [2], the doubly salient permanent magnet (DSPM) machine, incorporating the structure of SR machines and the use of PM materials, was proposed to work as a single-phase generator. Recently, it has been revealed that the polyphase DSPM machine can offer higher efficiency, higher power density and better controllability than its counterparts, including the SR and induction machines [3], [4].

The purpose of this paper is to propose a novel 3-phase 12/8-pole DSPM machine particularly for wind power generation. This DSPM generator can offer higher efficiency, higher power density and better controllability than both the SR and induction generators. The key is to design a novel machine structure, and to devise the system operation. In Section II, the system configuration and speed constraint of the 12/8-pole DSPM wind generator will be described. Section III will be

This work was supported and funded by a grant from Research Grants Council of Hong Kong Special Administrative Region, China. devoted to the machine design, including the topological selection and electromagnetic analysis. The finite element method (FEM) is applied to analyze the static characteristics of the generator. The system modeling and simulation will be discussed in Section IV. The implementation and experimental verification will be given in Section V. Finally, conclusions will be drawn in Section VI.

\section{SySTEM CONFIGURATION AND SPEED CONSTRAINT}

Fig. 1 shows the system configuration, which consists of a wind turbine for capturing wind power, a 3-phase DSPM generator for electromechanical energy conversion, a 3-phase full-bridge rectifier for AC-DC conversion, a buck converter for DC voltage regulation, a battery for electrical energy storage, and a single phase or 3-phase inverter for DC-AC conversion.

The rated speed of the DSPM generator, which dictates the whole size of the generator, can be determined by the wind energy equation developed by a wind turbine. The net electrical energy produced by a wind turbine system depends on the speed of the wind passing through its swept area and the efficiencies of its components. In [5], for a horizontal-axis wind turbine, the actual mechanical output power $P_{\text {mech }}$ is typically expressed as:

$$
P_{\text {mech }}=\frac{1}{2} C_{p} \rho v_{w}^{3} A
$$

where $C_{p}$ is the coefficient of wind power with a typical value of 0.4 or below, $\rho$ is the air density, $v_{w}$ is the wind velocity and $A$ is the swept area of wind turbine rotor. The value of $C_{p}$ varies with $\beta$, the ratio of the wind turbine's blade tip speed to the wind speed:

$$
\beta=\frac{\omega R}{v_{w}}
$$

where $R$ is the radius of blades and $\omega$ is the angular speed of the wind turbine shaft. When $\beta$ takes the specific value $\beta_{\max }$, the characteristic of $C_{p}$ has single maximum [6]. It is obvious that the shaft speed should change with the wind speed to extract maximum power from the wind. When the turbine is 


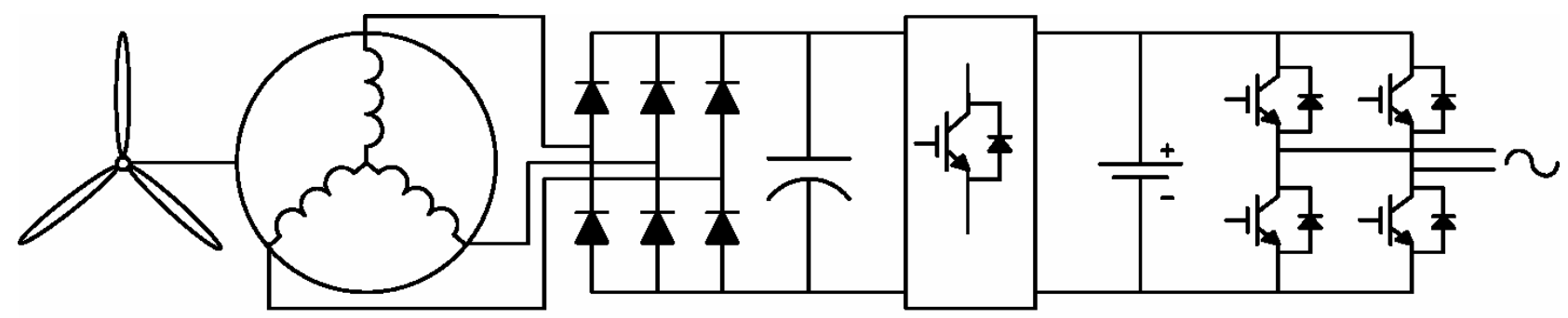

Figure 1. System configuration.

running at $\beta_{\max }$, the output power can be expressed as:

$$
P_{\text {mech }}=\frac{1}{2}\left(C_{p \max } \pi R^{2} \rho\right) v_{w}^{3} .
$$

The item $\left(C_{p \max } \pi R^{2} \rho\right)$ is a constant with a given wind turbine. Thus the output power varies with the cubic wind speed, and $P_{\text {mech }}$ can be rewritten as:

$$
P_{\text {mech }}=\frac{1}{2}\left(\frac{C_{p \max } \pi R^{5} \rho}{\beta_{\max }^{3}}\right) \omega^{3} .
$$

It should be noted that the rotor speed of a small variablespeed direct-drive wind generator is typically below $1000 \mathrm{rpm}$.

\section{MACHINE DESIGN}

\section{A. Topological Selection}

There is a wide range of possible combinations of phase number and stator and rotor pole numbers that can be chosen for DSPM generator design. In accordance with the basic operation principle of the DSPM generator, the general relationship among $N_{s}, N_{r}$, and $m$ are given by:

$$
\left\{\begin{array}{l}
N_{s}=2 m k \\
N_{r}=N_{s} \pm 2 k
\end{array}\right.
$$

where $N_{s}$ and $N_{r}$ are the number of stator and rotor poles, respectively, $m$ is the number of phases, and $k$ is a positive integer. When the generator runs at the speed of $n$, the frequency of each phase back EMF is given by:

$$
f=\frac{N_{r} n}{60} .
$$

To minimize the iron losses in poles and yokes, the number of rotor poles is usually less than that of stator poles. For example, $N_{s} / N_{r}=8 / 6$ and $12 / 8$ are possible configurations of the DSPM generator. Comparing these two types of machines which run at the same speed, the 12/8-pole machine has the advantages over 8/6-pole one, namely smaller number of phases, higher power density and simpler system configuration and control.
The DSPM generator is the key of wind power generating system. Fig. 2 shows the cross-section of the proposed 3-phase 12/8-pole DSPM generator. It has 12 salient poles in the stator and 8 salient poles in the rotor. There are 4 pieces of PM material, namely the neodymium-iron-boron (Nd-Fe-B) with a linear demagnetizing characteristic, placed inside the stator yoke to provide field excitation. The two coils on the diametrically opposite stator poles are connected to form a winding, and the two relevant windings are also connected in series to form a phase winding in the stator. Since there are no PMs, no brushes and no windings in the rotor, it offers a very simple rotor structure and low rotor inertia.

There are two types of rotor for selection: one is unskewed rotor which produces square waves of back EMF and current, the other is the skewed rotor which produces sinusoidal waves of back EMF and current. The one offering a higher power density will be selected for this DSPM generator.

For a machine with sinusoidal waveforms, when its back EMF $e_{s}$ and phase current $i_{s}$ are in phase, the average power $P_{s}$ of the machine can be expressed as:

$$
P_{s}=\frac{1}{\pi} \int_{0}^{\pi} e_{s}(\omega \mathrm{t}) i_{s}(\omega \mathrm{t}) \mathrm{d} \omega \mathrm{t}=\frac{1}{2} E_{m} I_{m}
$$

where $E_{m}$ and $I_{m}$ are the amplitudes of the phase back emf and current with sinusoidal waveform, respectively.

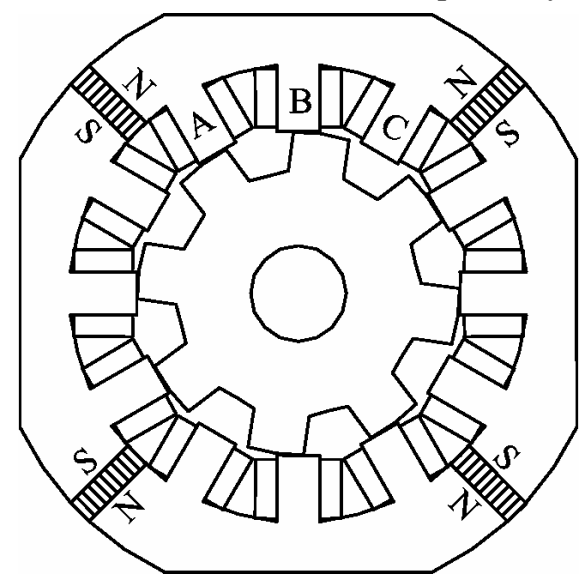

Figure 2. 3-phase 12/8-pole DSPM generator. 
For a machine with trapezoidal waveform as shown in Fig. 3 , its back EMF $e_{t}$ and phase current $i_{t}$ can be expressed as:

$$
\begin{aligned}
& e_{t}= \begin{cases}0 & \left(0 \leq \omega \mathrm{t}<\alpha_{1}\right) \\
\frac{E_{t m}}{k_{1} \pi}\left(\omega \mathrm{t}-\alpha_{1}\right) & \left(\alpha_{1} \leq \omega \mathrm{t}<\alpha_{1}+k_{1} \pi\right) \\
E_{t m} & \left(\alpha_{1}+k_{1} \pi \leq \omega \mathrm{t}<\alpha_{1}+\left(k_{1}+k_{2}\right) \pi\right) \\
\frac{-E_{t m}}{k_{1} \pi}\left(\omega \mathrm{t}-\alpha_{2}\right) & \left(\alpha_{1}+\left(k_{1}+k_{2}\right) \pi \leq \omega \mathrm{t}<\alpha_{2}\right) \\
0 & \left(\alpha_{2} \leq \omega \mathrm{t}<\pi\right)\end{cases} \\
& i_{t}= \begin{cases}0 & \left(0 \leq \omega \mathrm{t}<\alpha_{1}\right) \\
\frac{I_{t m}}{k_{1} \pi}\left(\omega \mathrm{t}-\alpha_{1}\right) & \left(\alpha_{1} \leq \omega \mathrm{t}<\alpha_{1}+k_{1} \pi\right) \\
I_{t m} & \left(\alpha_{1}+k_{1} \pi \leq \omega \mathrm{t}<\alpha_{1}+\left(k_{1}+k_{2}\right) \pi\right) \\
\frac{-I_{t m}}{k_{1} \pi}\left(\omega \mathrm{t}-\alpha_{2}\right) & \left(\alpha_{1}+\left(k_{1}+k_{2}\right) \pi \leq \omega \mathrm{t}<\alpha_{2}\right) \\
0 & \left(\alpha_{2} \leq \omega \mathrm{t}<\pi\right)\end{cases}
\end{aligned}
$$

When $e_{t}$ and $i_{t}$ are in phase, the average power $P_{t}$ of this machine is given by:

$$
P_{t}=\frac{1}{\pi} \int_{0}^{\pi} e_{t}(\omega \mathrm{t}) i_{t}(\omega \mathrm{t}) \mathrm{d} \omega \mathrm{t}=\frac{1}{3}\left(2 k_{1}+3 k_{2}\right) E_{t m} I_{t m}
$$

By using (7) and (10), the power ratio of the sinusoidal to trapezoidal DSPM generators can be obtained as:

$$
\frac{P_{s}}{P_{t}}=\left(\frac{3}{4 k_{1}+6 k_{2}}\right)\left(\frac{E_{m} I_{m}}{E_{t m} I_{t m}}\right) .
$$

Based on the same phase current and air-gap flux in each generator, the output power of different waveforms generator can be compared with the sinusoidal one. The RMS value of phase current with trapezoidal waveform can be expressed as:

$$
I_{t}=\sqrt{\frac{1}{\pi} \int_{0}^{\pi} i_{t}^{2} d \omega \mathrm{t}}=\frac{I_{t m}}{3} \sqrt{6 k_{1}+3 k_{2}} .
$$
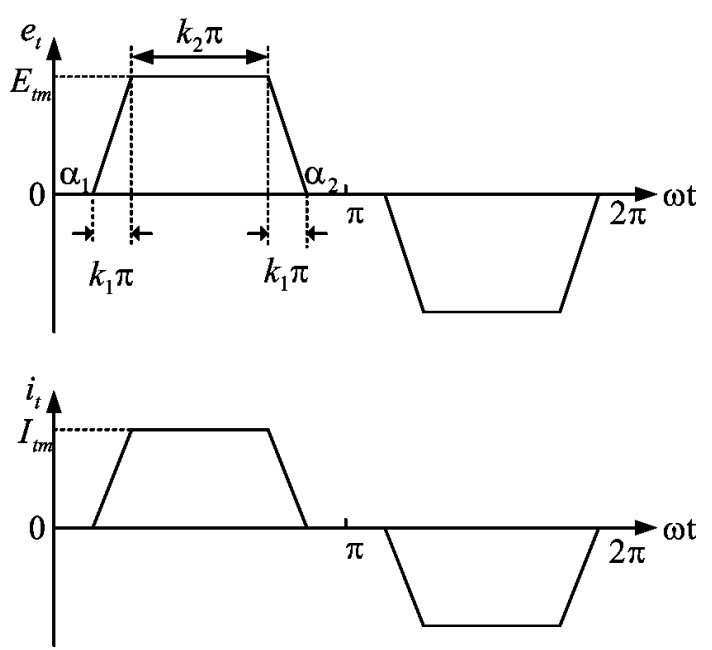

Figure 3. Trapezoidal waveform.
On the other hand, the RMS value of phase current with sinusoidal waveform is given by $I_{s}=I_{m} / \sqrt{2}$. Since $I_{t}=I_{s}$, the current ratio of the sinusoidal to trapezoidal waveforms can be obtained as:

$$
\frac{I_{m}}{I_{t m}}=\frac{1}{3} \sqrt{12 k_{1}+6 k_{2}} .
$$

Similarly, the air-gap flux can be represented by the averaged back EMF:

$$
\left\{\begin{array}{l}
\int_{0}^{\pi} E_{m} \sin \omega \mathrm{td} \omega \mathrm{t}=2 E_{m} \\
\int_{0}^{\pi} e_{t} \mathrm{~d} \omega \mathrm{t}=\left(k_{1}+k_{2}\right) \pi E_{t m}
\end{array} .\right.
$$

Hence, the EMF ratio of the sinusoidal to trapezoidal waveforms can be obtained as:

$$
\frac{E_{m}}{E_{t m}}=\frac{\pi}{2}\left(k_{1}+k_{2}\right) \text {. }
$$

Substituting (13) and (15) into (11), the power ratio can be rewritten as:

$$
\frac{P_{s}}{P_{t}}=\frac{\left(k_{1}+k_{2}\right) \pi}{2} \sqrt{\frac{3}{4 k_{1}+6 k_{2}}} .
$$

By taking $k_{1}=0$ and $k_{2}=2 / 3$, the trapezoidal wave becomes a square wave with a conduction angle of $120^{\circ}$. Table I compares the power ratios between the square wave and sinusoidal wave DSPM generators. It can be found that the square wave generator can produce more power output (namely, additional 10.3\%) than the sinusoidal one. Therefore, the unskewed rotor is selected for this wind generator.

TABLE I. POWER RATIO OF SINUSOIDAL TO SQUARE WAVE GENERATORS

\begin{tabular}{|c|c|c|c|c|}
\hline \multicolumn{2}{|c|}{ Waveform } & $k_{1}$ & $k_{2}$ & $P_{s} / P_{t}$ \\
\hline $120^{\circ}$ Square wave & \multicolumn{1}{|l|}{} & & & \\
\hline Sinusoidal wave & & & & \\
\hline
\end{tabular}

B. Electromagnetic Analysis

By using the FEM, the static characteristics of the proposed DSPM generator are analyzed. For simplicity, the two dimensional FEM is adopted. The corresponding nonlinear partial differential equation is expressed as:

$$
\frac{\partial}{\partial x}\left(v \frac{\partial A_{z}}{\partial x}\right)+\frac{\partial}{\partial y}\left(v \frac{\partial A_{z}}{\partial y}\right)=-\left(J_{z}+J_{p m}\right)
$$

where $A_{z}$ and $J_{z}$ are the $\mathrm{z}$ components of vector magnetic potential A and current density $\mathrm{J}$, respectively, $J_{p m}$ is the equivalent surface current density of PMs, and $v$ is the 
reluctivity. Both the nonlinear characteristics of the iron core and PMs are taken into account.

The magnetic field distribution of the proposed 12/8-pole DSPM generator under no-load and full-load are shown in Fig. 4. It can be seen that the no-load flux distribution is mainly symmetric with only a minor distortion due to the slot effect. It can also be found that the flux is mainly concentrated at the overlapping area of the stator and rotor teeth, and the leakage flux between the PM poles is negligibly small. Moreover, the armature reaction effect is insignificant because the field is mainly excited by the PMs.

Similarly, by using the FEM, the flux linkages and inductances of the proposed 12/8-pole DSPM generator can be obtained. Fig. 5 shows the PM flux linkage with respect to the rotor angle, while Fig. 6 shows the inductance characteristics with respect to both the armature current and rotor angle.

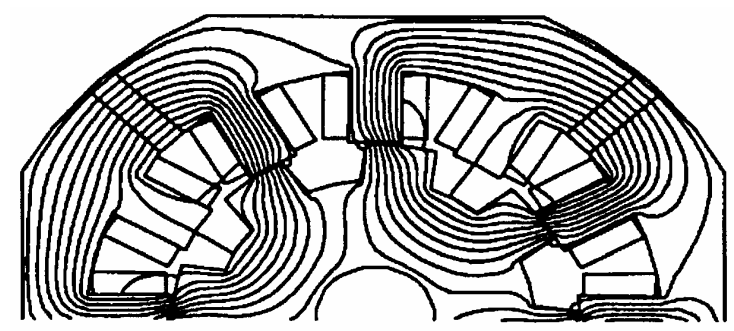

(a)

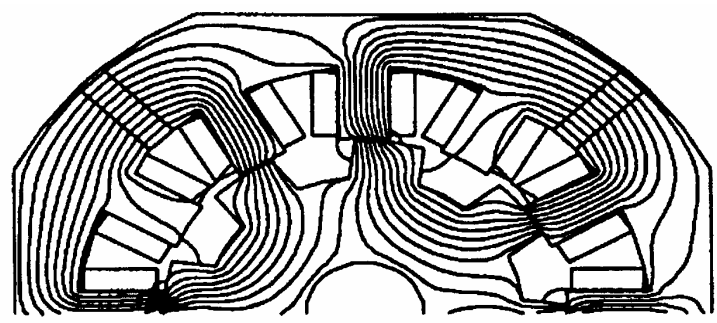

(b)

Figure 4. Magnetic field distributions using FEM. (a) No-load. (b) Full load.

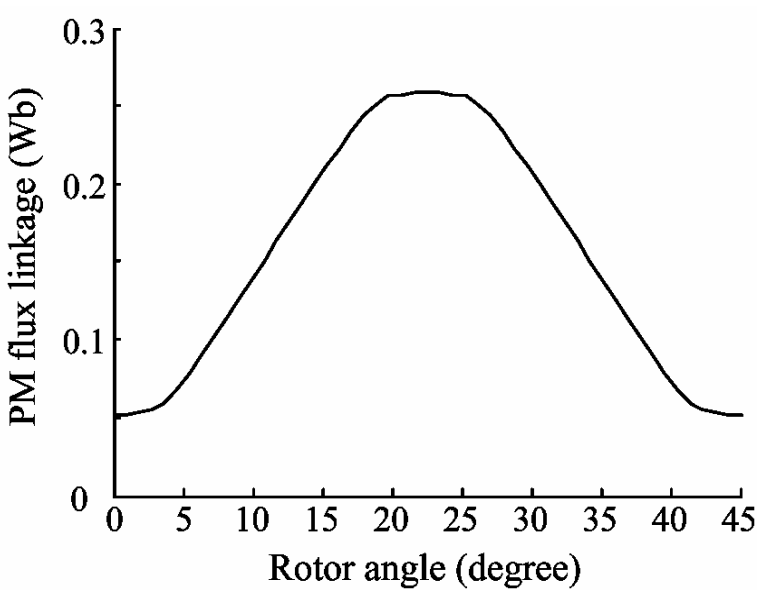

Figure 5. PM flux linkage using FEM.

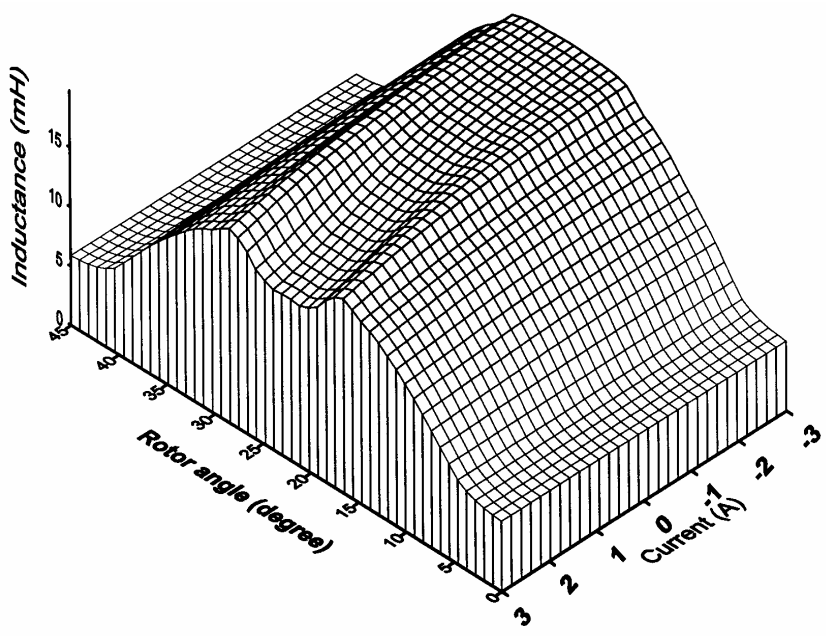

Figure 6. Inductance characteristics using FEM.

\section{System ModELING AND SimUlation}

\section{A. System Modeling}

Based on the flux linkages and inductances derived from using the FEM, the induced EMF $e$ can be calculated by:

$$
e=\frac{d \psi}{d t}=u+R i
$$

where $\psi$ is the flux linkage, $u$ is the terminal voltage, $R$ is the phase resistance and $i$ is the phase current. Considering a current flows from the stator winding to the external load, the flux linkage $\psi$ is presented as:

$$
\psi=\psi_{p m}-L i
$$

where $\psi_{p m}$ is the PM induced flux linkage, and $L i$ is the flux linkage due to armature reaction.

Therefore, the three phase terminal voltages are:

$$
\begin{aligned}
& {\left[\begin{array}{l}
u_{A} \\
u_{B} \\
u_{C}
\end{array}\right]=\left[\begin{array}{l}
\frac{d \psi_{p m A}}{d t} \\
\frac{d \psi_{p m B}}{d t} \\
\frac{d \psi_{p m C}}{d t}
\end{array}\right]-\left[\begin{array}{ccc}
R_{A}+\frac{d L_{A}}{d t} & 0 & 0 \\
0 & R_{B}+\frac{d L_{B}}{d t} & 0 \\
0 & 0 & R_{C}+\frac{d L_{C}}{d t}
\end{array}\right] } \\
&-\left[\begin{array}{c}
L_{A} \frac{d i_{A}}{d \theta_{A}} \\
L_{B} \frac{d i_{B}}{d \theta_{B}} \\
i_{B} \\
i_{C} \frac{d i_{C}}{d \theta_{C}}
\end{array}\right] \omega
\end{aligned}
$$

where $u_{A}, u_{B}, u_{C}$ are the phase voltages, $\psi_{p m A}, \psi_{p m B}, \psi_{p m C}$ are the PM flux linkages, $R_{A}, R_{B}, R_{C}$ are the resistances, $L_{A}$, 
$L_{B}, L_{C}$ are the inductances, $i_{A}, i_{B}, i_{C}$ are the phase currents. and $\theta_{A}, \theta_{B}, \theta_{C}$ are the rotor positions, $\omega$ is the rotor angular velocity. The rotor positions are related by:

$$
\left\{\begin{array}{l}
\theta_{B}=\theta_{A}-\alpha \\
\theta_{C}=\theta_{A}-2 \alpha
\end{array}\right.
$$

where $\alpha$ is the phase position difference as given by:

$$
\alpha=\frac{\theta_{r}}{m}=15^{\circ}
$$

where $\theta_{r}$ is the rotor pole pitch. Moreover, the relationships of various variables among phases are given by:

$$
\left\{\begin{array}{l}
\psi_{A}\left(\theta_{A}\right)=\psi_{B}\left(\theta_{B}\right)=\psi_{C}\left(\theta_{C}\right) \\
i_{A}\left(\theta_{A}\right)=i_{B}\left(\theta_{B}\right)=i_{C}\left(\theta_{C}\right) \\
u_{A}\left(\theta_{A}\right)=u_{B}\left(\theta_{B}\right)=u_{C}\left(\theta_{C}\right)
\end{array} .\right.
$$

\section{B. System Simulation}

Making use of the aforementioned system model, computer simulation is conducted to assess the performance of the DSPM generator. The Matlab/Simulink environment is adopted, since it takes the advantages of easy programming, high flexibility and powerful toolboxes. The corresponding power system block toolbox is particularly useful for simulation of electric machines such as the SR motor and DSPM motor [7]. The no-load EMF at the rated speed of 750 rpm is simulated as shown in Fig. 7. Consequently, the line voltage, line current and DC output voltage under full load at the rated speed of $750 \mathrm{rpm}$ are simulated as shown in Fig. 8, Fig. 9 and Fig. 10, respectively.

\section{IMPLEMENTATION AND EXPERIMENTAL VERIFICATION}

For exemplification, a low-power experimental setup is established. The proposed DSPM generator is prototyped, which confirms its high power density and robustness. The corresponding key data are listed in Table II. The natural wind characteristics are emulated by real-time controlling the programmable DC dynamometer. Fig. 11 shows the measured no-load EMF waveform of the proposed generator operating under full load at the rated speed of $750 \mathrm{rpm}$. Fig. 12 shows the

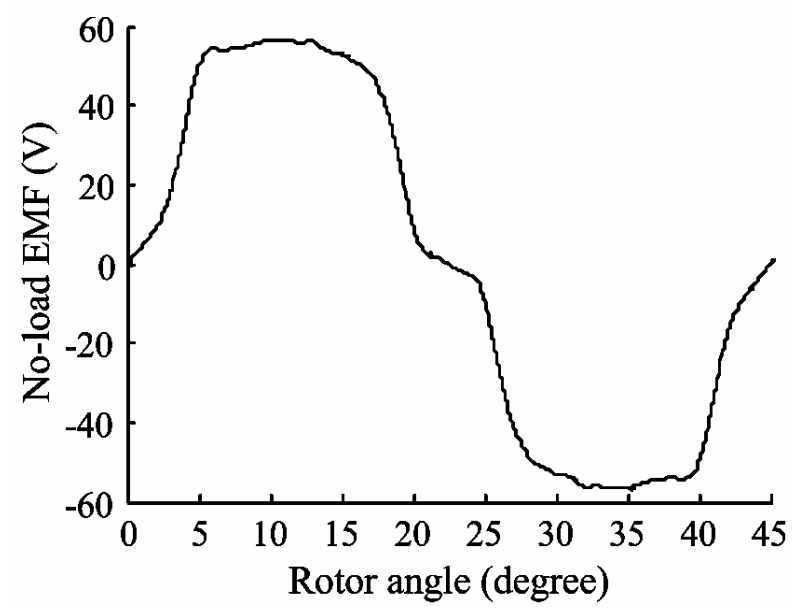

Figure 7. Simulated no-load EMF waveform.

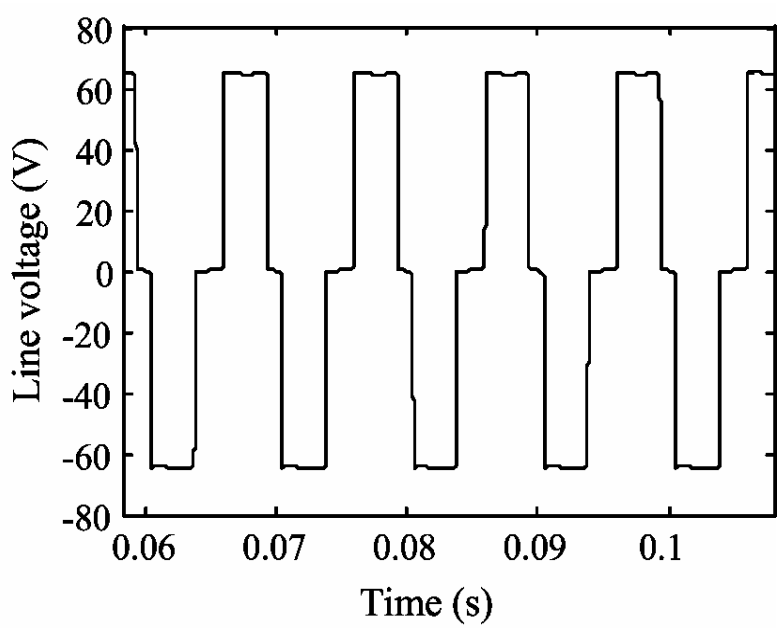

Figure 8. Simulated line voltage waveform.

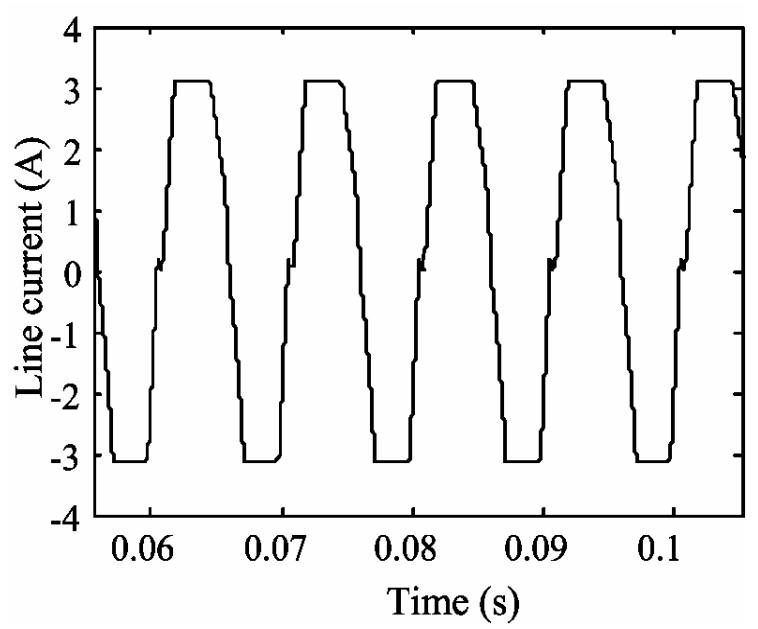

Figure 9. Simulated line current waveform.

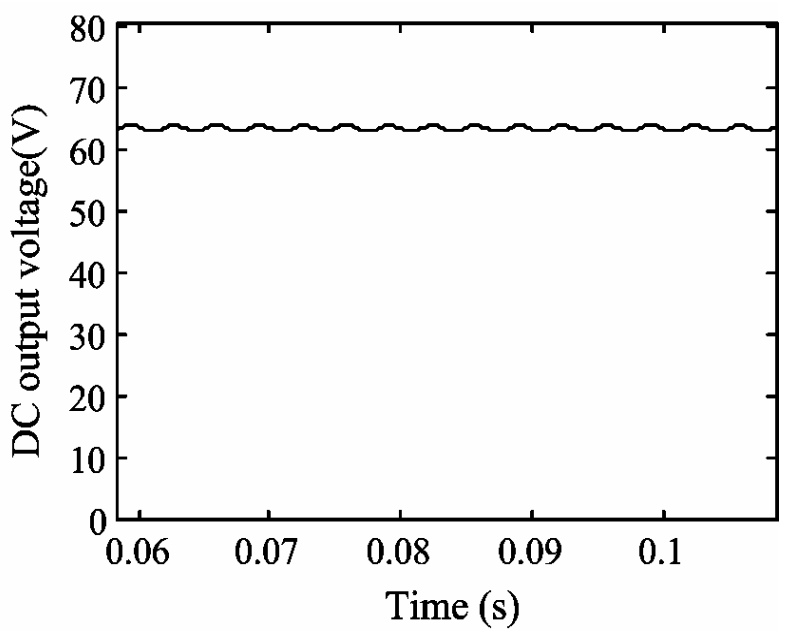

Figure 10. Simulated DC output waveform. 
measured line voltage and current waveforms at the rated load and rated speed. Fig. 13 shows the measured DC output voltage waveform under full load at the rated speed of $750 \mathrm{rpm}$. As expected, the measured waveforms closely agree with the simulation waveforms.

A series of no-load experiment are conducted at various rotor speeds. The measured output line voltage is compared with the simulated one as shown in Fig. 14. It can be seen that they have a good agreement. Also, the measured output voltage is almost linearly proportional to the rotor speed.

Through the 3-phase rectifier, the variable output voltage of the 12/8-pole DSPM generator is rectified to a variable DC voltage. The $\mathrm{DC}$ voltage of the rectifier varied with the wind speed. Thus, a buck converter is employed to regulate the DClink voltage of the inverter. Considering the nominal battery voltage $(28 \mathrm{~V})$ as the critical voltage of the DC-link, the wind power generation directly supplies the inverter and charging the battery, when the speed is over $330 \mathrm{rpm}$. Otherwise the battery supplies the inverter to produce the AC output. Moreover, Fig. 15 shows the measured voltage and current waveforms of the inverter AC output with the generator operating at the rated speed of $750 \mathrm{rpm}$ and a resistive load of $250 \Omega$.

\section{Table II Data of Prototype}

\begin{tabular}{lc}
\hline Stator inner diameter $(\mathrm{mm})$ & 75 \\
Stack length $(\mathrm{mm})$ & 150 \\
Air-gap length $(\mathrm{mm})$ & 0.45 \\
Stator pole number & 12 \\
Rotor pole number & 8 \\
Stator pole arc (degree) & 15 \\
Rotor pole arc (degree) & 20 \\
Stator pole height (mm) & 15 \\
Rotor pole height (mm) & 9 \\
Number of turns/phase & 260 \\
Magnet remanence $(\mathrm{T})$ & 1.08 \\
Magnet coercive force $(\mathrm{A} / \mathrm{m})$ & 843760 \\
Stator resistance per phase $(\Omega)$ & 5.47 \\
\hline
\end{tabular}

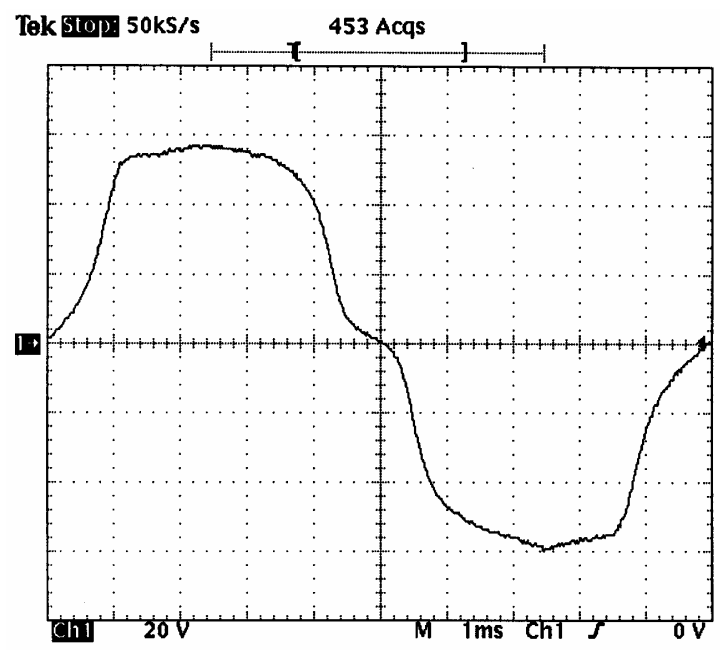

Figure 11. Measured no-load EMF waveform (20 V/div, $1 \mathrm{~ms} / \mathrm{div})$.

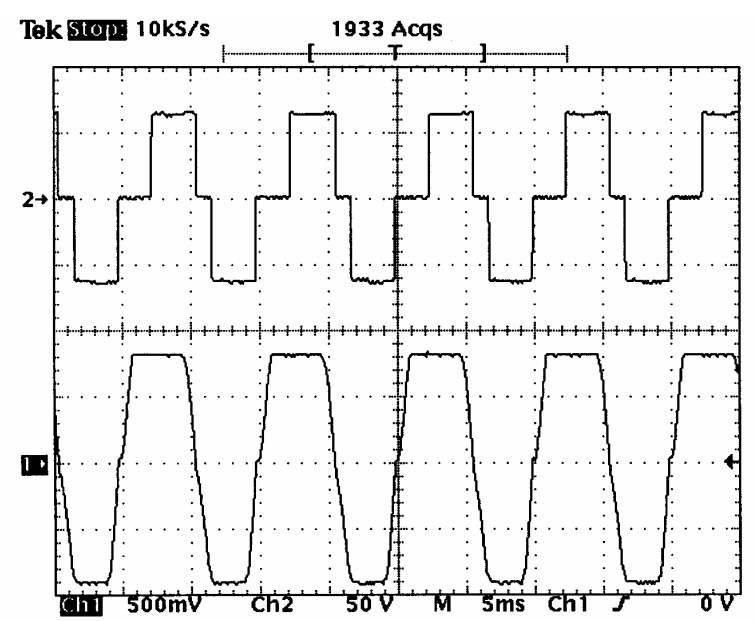

Figure 12. Measured line voltage and current waveform ( $50 \mathrm{~V} / \mathrm{div}, 2 \mathrm{~A} / \mathrm{div}, 5$ $\mathrm{ms} / \mathrm{div})$.

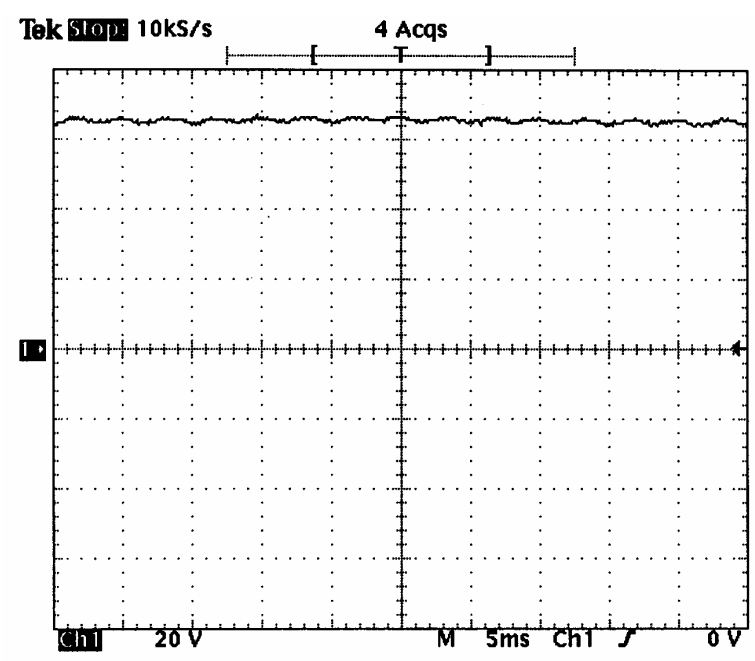

Figure 13. Measured DC output voltage waveform (20 V/div, $5 \mathrm{~ms} / \mathrm{div})$.

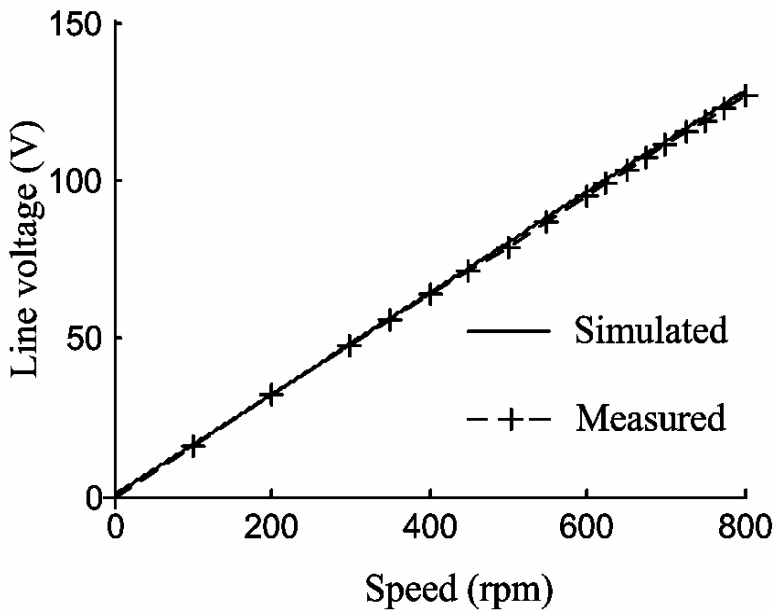

Figure 14. Simulated and measured no-load line voltages. 


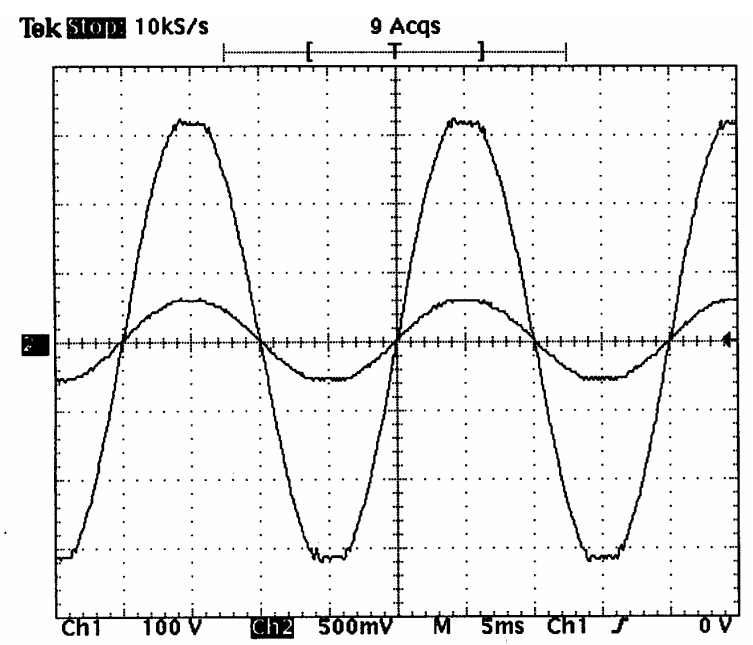

Figure 15. Measured inverter output voltage and current waveforms (100 $\mathrm{V} / \mathrm{div}, 2 \mathrm{~A} / \mathrm{div}, 5 \mathrm{~ms} / \mathrm{div}$ ).

Furthermore, the voltage regulations of the whole system at different load currents and different rotor speeds are assessed as shown in Fig. 16. It is obvious that the simulated and measured results have a very good agreement.

Finally, the system efficiencies at different load currents and rotor speeds are measured as shown in Fig. 17. It can be found that efficiencies are high over a wide range of load currents. Particularly, the efficiency under the full load of $3 \mathrm{~A}$ at the rated speed of $750 \mathrm{rpm}$ is over $82 \%$.

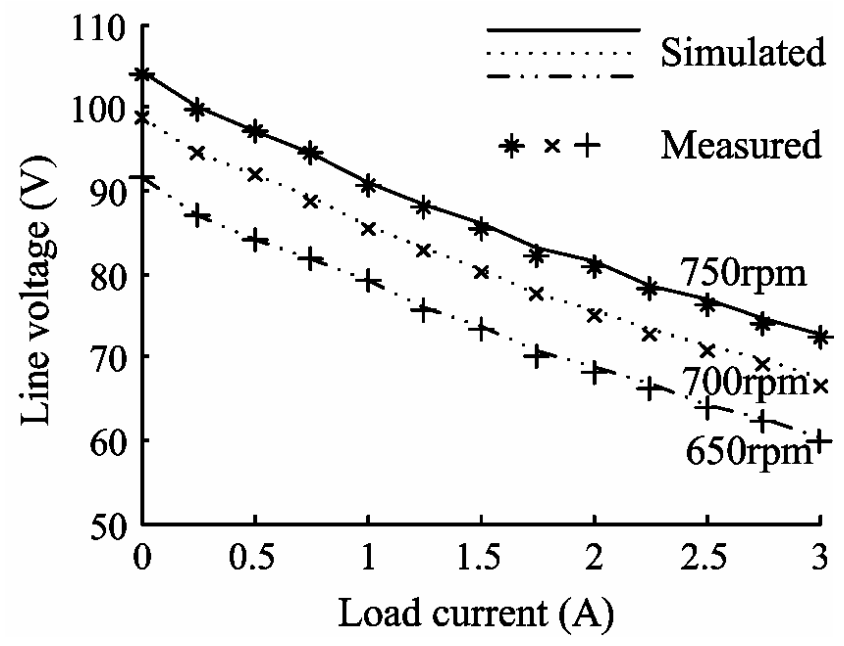

Figure 16. Simulated and measured output voltage regulation.

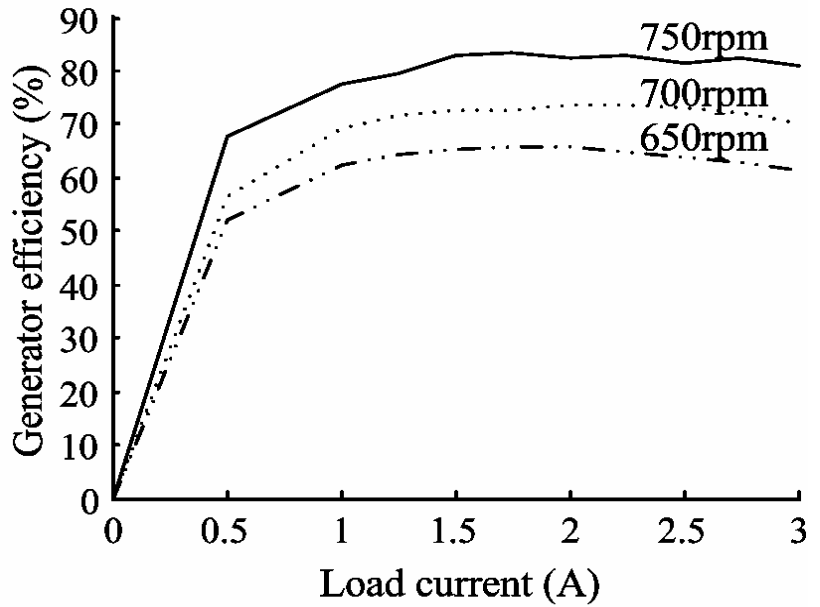

Figure 17. Efficiency at various speeds.

\section{CONCLUSION}

In this paper, the design, analysis and implementation of a novel 3-phase 12/8-pole DSPM generator have been presented. This DSPM generator possesses a novel machine structure which can offer high power density, high robustness and low manufacturing lost. Also, the proposed generator system can allow for high efficiency operation over wide ranges of load current and rotor speed. Both computer simulation and experimental results confirm the validity of the proposed DSPM machine for wind power generation.

\section{REFERENCES}

[1] H. Chen, C. Zhang and X.C. Zhao, "Research on the switched reluctance wind generator system," IEEE International Conference on Systems, Man, and Cybernetics, 2001, pp. 1936-1941.

[2] B. Sarlioglu, Y.F. Zhao and T.A. Lipo, "A novel doubly salient single phase permanent magnet generator," IEEE Industry Applications Society Annual Meeting, 1994, pp. 9-15.

[3] M. Cheng, K.T. Chau, C.C. Chan and Q. Sun, "Control and operation of a new 8/6-pole doubly salient permanent magnet motor drive," IEEE Transactions on Industry Applications, Vol. 39, No. 5, 2003, pp. 1363 1371.

[4] M. Cheng, K. T. Chau and C. C. Chan, "Static characteristics of a new doubly salient permanent magnet motor," IEEE Transactions on Energy Conversion, Vol. 16, No. 1, 2001, pp. 20-25.

[5] J. Chen, C. V. Nayar,L. Xu, "Design and finite-element analysis of an outer-rotor permanent magnet generator for directly coupled wind turbines," IEEE Transactions on Magnetics, Vol. 36, No. 5, 2000, pp. 3802-3809.

[6] M.R. Patel, Wind and Solar Power Systems. CRC Press, 1999.

[7] F. Soares and P.J. Costa Cranco, "Simulation of a 6/4 switched reluctance motor based on Matlab/Simulink environment," IEEE Transactions on Aerospace and Electronic Systems, Vol. 37, No. 3, 2001, pp. 989-1009. 